\author{
Беата Рыцельска
}

Щецинский университет (Щециин, Польша)

\title{
О КОЛИЧЕСТВЕННОЙ ИКОНИЧНОСТИ В СКАЗКЕ АЛЕКСЕЯ ТОЛСТОГО ЗОЛОТОЙ КЛЮЧИК ИЛИ ПРИКЛЮЧЕНИЯ БУРАТИНО И ЕЕ ПОЛЬСКОМ ПЕРЕВОДЕ
}

\section{СКАЗКА И ИКОНИЧНОСТЬ}

Сказка представляет собой один из жанров народного либо литературного творчества. Рассказывает о вымышленных лицах и событиях, в которых часто участвуют антропоморфные животные и волшебные силы. Изучению сказок посвящены многочисленные публикации. В них они классифицируются по авторству (фольклорные и авторские или литературные сказки) и по видовым особенностям, определяются признаки разновидностей сказок, отличие сказок от других схожих жанров, типы героев, композиция, поэтика. Сказочный текст оказывается хорошим источником для исследования различных типов иконичности, так как в нем сосредоточивается более полное, по сравнению с другими видами текстов, использование иконических способов категоризации действительности. Замечается также, что когнитивистский подход к анализу сказок весьма редко встречается в научной литературе (см. примеры в Библиографии).

Проблема иконичности знака издавна занимает исследователей. В начале XX века Чарльз С. Пирс выделил икону среди остальных типов знаков - индексов и символов. Опирался при этом на критерий соотношения элементов знака, описанных Фердинандом де Соссюром: означающим и означаемым, формой и содержанием. Иконы как знаки объединяет отношение сходства двух элементов, причем их форма уподобляется содержанию, и, соответственно, значение отражается в форме. В случае индексов форма указывает на содержание (например, некоторые дорожные знаки, язык тела, в естественном языке - указательные местоимения и наречия), а при символических знаках связь формы и значения имеет конвенциональный характер. Согласно положениям когнитивной лингвистики, общая идея типоло- 
гии знаков опирается, в основном, на мотивированность формы знака его содержанием, не на арбитральность знака, как утверждают представители структурной лингвистики.

В результате классификации иконических знаков выделены их типы - метафора, иконичность образная и диаграмматическая. Последний представлен тремя разновидностями связи формы и содержания, которые опираются на принципы количества, порядка слов и проксимальности/удаленности (дистантности) слов в высказывании. Иконичность есть один из аспектов конструирования событий в языке, разработанный создателем теории образности, Рональдом Лангакером. Основная цель исследования иконичности состоит в определении языковых средств, связанных с этим способом категоризации мира, и выявлении впоследствии приемов концептуализации действительности говорящими.

До настоящего времени по поводу иконичности опубликована богатая литература. Начало изучению явления положили англоязычные работы, со временем результаты исследований стали доступными более широкому кругу заинтересованных. С тех пор концепция иконичности продолжает излагаться и развиваться в последующих трудах, в том числе польских и русских. В последнее время на тему иконичности в польской научной литературе появились первые, тем более ценные, публикации (см. Библиографию). Результаты, помещенные в них, показывают, что изучение языков позволяет познать доступные в них специфические средства кодирования явлений, относящиеся, между прочим, к иконическим способам конструирования того или иного явления. Исследования по иконичности подтверждают положение теории категоризации о том, что в знаке проявляются познавательные возможности говорящих, а к общим свойствам носителей языков принадлежит их умение сравнивать разнородные явления и находить или устанавливать между ними сходства.

\section{КОЛИЧЕСТВЕННАЯ ИКОНИЧНОСТЬ В ИСХОДНОМ И ПЕРЕВОДНОМ TEКСТАХ}

Количественная иконичность как один из принципов диаграмматичности проявляется в речи за счет употребления разнородных конструкций. Персонажи сказки А. Н. Толстого особенно часто используют определенные приемы кодирования воспринимаемой ими действительности. Среди них, в первую очередь, выделяется фонетическая редупликация. Сущность повторения однородных звуков того или другого слова заключается, главным образом, в отражении большой интенсивности явления, о котором речь идет в высказыва- 
нии. При помощи удлиненного таким образом словесного знака реализуется основная иконическая формула больше формь - больше содержания. Например, в приведенных ниже отрывках исходного и переводного текстов

(Р) - Оччччень мне нужны советы старого сверчка... (с. 17)

(П) Strrrrrrasznie potrzebne mi są rady starego świerszcza... (c. 13)

кодируется высокомерно-презрительное отношение, недостаток уважения Буратино к старому Сверчку, пытавшемуся поделиться с ним своим жизненным опытом. В этом случае сильное пренебрежение, выраженное длинной формой наречия оччччень - strrrrrasznie, поддерживается фразовой интонацией, которая в работах по фонетике русского языка обозначается как ее седьмая разновидность (интонационная конструкция ИК-7). Она появляется, между прочим, в высказываниях такого типа, как приведенное выше, т.е. при выражении экспрессивного несогласия и отрицания, и имеет соответствие в польской речи. Употребление данной конструкции связано здесь с экспрессией пренебрежения, иронии, а также отрицания „отнюдь мне не нужны советы Сверчка”. Передаче такого сложного значения дополнительно способствует обратный порядок расположения слов в предложении. Фигурой концептуализации события являются в нем понятия весьма пренебрежительного отношения и отрицания процесса, кодируемые удлиненным наречием оччччень - strrrrrasznie, вынесенным в начало фразы, имеющей инверсионный характер. Сравним обыкновенный порядок слов, который выражает противоположное понятие - испытываемую Буратино нужду в советах Сверчка: Мне очень нужны советь cтарого сверчка. - Sa mi strasznie potrzebne rady starego świerszcza. Таким образом, фонетическая редупликация во взаимодействии с другими языковыми средствами - инверсией и соответствующей интонацией, сопровождающей конструкцию события, - подчеркивает в обоих фрагментах чувство сильного пренебрежения и нежелание Буратино слушать советы Сверчка. Отражает также познавательную способность носителей языка - их умение подбирать такие языковые средства, коммуникативная функция которых направлена на обеспечение когерентной передачи концептуализации явления.

В другом примере:

(Р) - Мне ужжжжжжасно хочется посмотреть кукольный театр! - сквозь слёзы сказал Буратино. (с. 24)

(П) - Tak bym strrasznie chciał zobaczyć teatr kukiełek - ze łzami w oczach powiedział Buratino. (c. 18)

степень интенсивности желания Буратино в переводном тексте (strrasznie) значительно ниже по сравнению с исходным текстом. Реализуемая в подлиннике формула больше формьл - больше содержания сменяется в переводе 
формулой меньше формы - меньше содержания. Она, однако, по отношению к обыкновенному, ничем не выделяющемуся количеству формы (ужасно - strasznie), которая структурирует большую интенсивность признака, превышающую обычную меру, норму, все-таки, отличается большим количеством формы, отражающим концептуализацию высшей степени проявления признака (strrasznie).

В свою очередь, в следующем примере:

(Р) - Ах, Буратино, Буратино, - проговорил сверчок, - брось баловство, слушайся Карло, без дела не убегай из дома и завтра начни ходить в школу. Вот мой совет. Иначе тебя ждут ужасные опасности и страшные приключения. За твою жизнь я не дам и дохлой сухой мухи.

- Поччччему? - спросил Буратино.

- А вот ты увидишь - поччччему, - ответил Говорящий Сверчок. (с. 17)

(П) - Ach, Buratino, Buratino - zagadał Świerszczyk - porzuć swawole, słuchaj Carla; jeśli nie masz po co, nie wychodź z domu i od jutra zacznij chodzić do szkoły. Oto moja rada, bo w przeciwnym razie czekają cię okropne niebezpieczeństwa i straszliwe przygody. I wtedy nie dam za twoje życie nawet zdechłej muchy.

- Dlaczego? - zapytał Buratino.

- Przekonasz się, dlaczego - odparł Gadający Świerszcz. (c. 13)

не сохраняется в переводе реализуемая в исходном тексте упомянутая выше формула больше формы - больше содержания. Степень интенсивности испытываемого Буратино сомнения не превышает в переводе общепринятую норму проявления эмоций. Обыкновенное количество формы, т.е. неудлиненное слово (Dlaczego?), показывает, что Буратино просто задает вопрос, ожидая получить интересующую его информацию.

Помимо фонетической редупликации, одним из способов отражения в речи принципа количественной иконичности, чаще всего приводимым исследователями, является в сказке повторение лексических единиц, а также синтаксических. На их основе заметно, что формулу больше формы - больше содержания конкретизируют не исключительно, хотя преимущественно, выражения со значением большой интенсивности явления. Так, имеются в виду следующие примеры конструкций:

- повторение отрицательных местоимений-существительных - помогает подчеркнуть отсутствие предмета и сильное эмоциональное отношение к этому факту говорящего. Эту функцию усиливает наличие частицы -то в составе местоимения ничего-то:

(Р) Ах, ничего-то, ничего-то не было у бедного Карло запасено на ужин! (с. 18)

(П) Ach, nic, nic, niestety, ani kąska nie miał stary Carlo w zapasie. (c. 14) 
Для выражения данного значения в переводе используются дополнительные к местоимениям nic, nic языковые средства: количественная конструкция ani kąska и модальное наречие niestety, которое кодирует субъективную эмоцию сочувствия повествователя по отношению к Карло, который, отметим, в исходном тексте характеризуется как бедныцй, а в переводе - как $\operatorname{stary}($ cmapыü).

- сложное разговорное наречие давным-давно, образованное повторением однокоренных компонентов; оно закреплено языковым узусом и выполняет синтаксическую функцию обстоятельства времени. Как преимущественную сферу его употребления источники указывают тексты, ориентированные на старую народную речь и фольклор ${ }^{1}$. Оно представляет собой сложное выражение, состоящее из суффиксальной формы $\partial a b \mu-b l м$, употребляющейся только препозитивно рядом с наречием на -о (давно $)^{2}$. Обозначает тот же признак, что и мотивирующее его прилагательное давний, но с оттенком усиления, также по отношению к простому наречию давно. Имеет значение большой темпоральной отдаленности называемого в тексте действия от точки отсчета - момента речи повествователя. Данная концептуализация соответствует принципу больше формы - больше содержания и конкретизируется понятием больщей давности процесса. Это выражение, употребленное во фразе, начинающей произведение А. Н. Толстого:

(Р) Давным-давно в городке на берегу Средиземного моря жил старый столяр Джузеппе, по прозванию Сизый Нос (с. 6).

(П) $W$ dawnych, dawnych czasach, w małej mieścinie nad brzegiem Morza Śródziemnego żył sobie stary stolarz Beppo, przezwany Sinym Nosem (c. 7)

переводится при помощи словесной редупликации $w$ dawnych, dawnych czasach. Она удлиняет наречие $w$ dawnych czasach, отличающееся значительно большей частотностью употребления. Это осложненное наречие совпадает с конструкцией давнылм-давно на уровне количественной иконичности, отражает также метафорическую концептуализяцию ВРЕМЕНИ как ВМЕСТИЛИЩА, которая, однако, в подлиннике отсутствует.

- повторение имен прилагательных - бльшее количество адъективов в высказывании (длиннылм-длиннылм) сообщает о концептуализации большой интенсивности признака, превышающей принятую носителями языка норму как наличие обыкновенного атрибута у того или другого явления. Например:

(Р) Нос вертелся, вывёртывался, так и остался - длинным-длинным, любопытным, острым носом. (с. 13)

${ }^{1}$ См. АГ-80, т. I, п. 981, сс. 399-400.

2 Ср. другие реализации данной схемы: бельмм-бело, черным-черно, полным-полно. См. там же. 
(П) (...) nos wiercił się i kręcił na wszystkie strony i został wreszcie taki, jak był - dtugi, wścibski i ostry nos. (c. 10)

В переводе теряется значение чрезмерно длинного носа, употребляется прилагательное $d$ tugi, которое выражает понятие длинного, но не сверх меры, предмета.

В свою очередь, в приведенном ниже примере

(Р) Не нужно забывать, что Буратино шёл всего первый день от рождения. Мысли у него были маленькие-маленькие, коротенькие-коротенькие, пустяковые-пустяковые. (с. 15)

(П) A nie trzeba zapominać, że Buratino miał dopiero jeden dzień. Myśli jego były jeszcze mate-malutkie, krótkie-króciutkie, głupie-głupiutkie. (c. 12)

значение высокой степени интенсивности признака кодируется за счет нагромождения взаимодействующих друг с другом языковых средств - повторения имен прилагательных, притом - с уменьшительно-ласкательным суффиксом -еньк-. Удлиненные таким образом слова маленькие, коротенькие профилируют большую степень качества предмета, который является очень малым, очень коротким по отношению к норме, выраженной мотивирующими прилагательными мальй, короткий. Их редупликация еще усиливает значение большого количества признака.

Выделенные в переводе конструкции не принадлежат к узуальным. По форме они не тождественны выражениям русского языка, употребленным в сказке, и не полностью соотносятся с ними по значению. Они отличаются несколько меньшей интенсивностью признака определяемого предмета (мыслей), которую кодирует соответственно меньшее количество формы. Сравним: с одной стороны, в сказке имеем дело с двукратным повторением одних и тех же прилагательных маленькие-маленькие, коротенькие-коротенькие с уменьшительно-ласкательным суффиксом -еньк- или без него в случае пустяковые-nустяковые, с другой стороны - с выражениями matemalutkie, krótkie-króciutkie, głupie-głupiutkie в переводном языке. Эти последние образуются за счет двух неодинаковых однокоренных прилагательных - первое из них выражается простой формой, другое - производной, образованной присоединением уменьшительно-ласкательного суффикса -( $i)$ $u t k-$, профилирующей большую интенсивность признака. Заметим также, что в исходном тексте и его переводе в выражениях маленькие-маленькие, коротенькие-коротенькие, małe-malutkie, krótkie-króciutkie отрицательная оценка мыслей отражается при помощи метафорической концептуализации ПРЕДМЕТОВ НИЧТОЖНЫХ ПО РАЗМЕРАМ. В свою очередь, выражение nустяковые-пустяковые воспроизводит понятие несложных мыслей при помощи метафоры ПРОСТЫХ ПРЕДМЕТОВ, в то время как употребленное в переводе осложненное прилагательное gtupie-gtupiutkie, определяющее 
мЫсли, опирается на метонимию ПРИЗНАК ПРЕДМЕТА ВМЕСТО ПРИЗНАКА ТОГО, КТО СОЗДАЛ ЭТОТ ПРЕДМЕТ.

- повторение междометия, связанное с концептуализацией очень большой интенсивности неприятного физиологического впечатления - неожиданной боли:

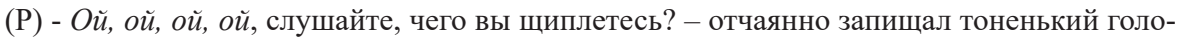
сок... (с. 8)

(П) - Ojej, proszę mnie nie męczyć! - zapiszczał błagalnie cieniutki głosik. (c. 7)

В переводном тексте в этом случае не сохраняется эквивалентность на иконическом уровне конструирования явления - меньшее количество формы соответствует концептуализации меньшей интенсивности неприятного ощущения, испытываемого героем сказки. Реализуемая формула - это меньше формы - меньше содержания.

- повторение простых предложений - в обоих текстах такой прием часто кодирует большую интенсивность действия, о котором говорится в предложении, например:

(Р) Задевая мягким крылом за его нос, Сплюшка ${ }^{3}$ повторяла:

- Не верь, не верь, не верь! (с. 40)

(П) Trącając go lekko skrzydłami w nos, sówka powtarzała:

- Nie wierz im, nie wierz im, nie wierz im! (c. 30)

В другой прагматической ситуации редупликация глагольных сказуемых попятился, попятился выполняет функцию большей растянутости действия во времени. В результате повторения одного и того же движения сказочный персонаж постепенно отдаляется от точки отсчета - полена и уроненного рубанка:

3 Отметим, что в переводе теряется имя совы Сплюшка. В подлиннике использовано название вида птиц - „сплюшка”. Сплюшки принадлежат к роду совки, к семейству совиных. В источниках на русском языке читаем, что сплюшки издают печальный мелодичный, посвист „сплюю” или „тьёёв”. Крик повторяется с интервалом 2-3 секунды. За крик птица и получила название. См. Материал из Википедии - свободной энциклопедии, https://ru.wikipedia. org/wiki/\%D0\%A1\%D0\%BF\%D0\%BB\%D1\%8E\%D1\%88\%D0\%BA\%D0\%B0.

В переводе вместо названия вида „сплюшка” употреблено уменьшительное название sówka, вероятно, по небольшому размеру птицы. Согласно систематике птиц, русскому названию вида „сплюшка” (лат. Otus scops) соответствует польское название „syczek zwyczajny”. В источниках на польском языке отмечается, что этот вид совы издает свисты „, kjuuut”. См. „Atlas rozpoznawania sów”. Syczek (Otus scops), http://sowy.sos.pl/atlas-rozpoznawania-sow/syczek-otus-scops/. Род „Otus” - это „мелкая, ушатая сова” („mała, uszata sowa”), у нее пучки перьев по бокам головы. См. „Род Совки - Otus”, http://www.apus.ru/site.xp/052052057.html. Вероятно, в основе разных названий данного вида совы лежат звуки, по-разному воспринимаемые носителями обоих языков. 
(Р) Джузеппе уронил рубанок, попятился, попятился и сел прямо на пол: он догадался, что тоненький голосок шёл изнутри полена. (с. 8)

(П) Beppo wypuścił z rąk toporek, cofnąt się o krok, o drugi - i aż przysiadł ze strachu na podłodze $(\ldots)$ (c. 8$)$

В польском переводе глагольная конструкция с предложными сочетаниями в роли обстоятельства способа действия cofnąt się o krok, o drugi выражает перечисление шагов, профилирует увеличившееся на определенное количество шагов расстояние героя сказки от точки отсчета.

Количественная иконичность обнаруживается в сказке в случае применения еще других языковых средств, не только за счет фонетической, лексической, синтаксической редупликаций, но также за счет более длинных словесных форм, полученных различными словообразовательными способами. Выше обратили на себя внимание как компоненты осложненных второстепенных членов предложения удлиненные прилагательные с уменьшительно-ласкательным суффиксом -еньк-, отрицательное местоимение с усилительной частицей -то (ничего-то). Кроме них имеются в виду слова, чаще всего имена прилагательные, образованные суффиксальным или префиксально-суффиксальным способами, а также наречия и имена существительные, образованные суффиксальным способом. Речь идет о следующих конструкциях, которые наличествуют в сказке, и об аффиксах, участвующих в их построении:

- суффикс -оват- (-еват-) и соответствующий ему в польском языке суффикс - $(k) a w$ - вносят в производную основу прилагательного значение ослабленного качества предмета ('слегка, несколько'), определяемого прилагательным, наличия качества лишь в небольшой степени. К таким конструкциям относятся имеющиеся в обоих языках прилагательные типа зеленоватый - zielonkawy, в сопоставлении с мотивирующими их основами более сложные как по форме, так и по содержанию. Джон Р. Тайлор отмечает, что длина языкового выражения может отражать не только больше содержания (например, множественное значение выражается более длинной словесной формой), но может также отражать сложность символизируемого ими понятия (см.: Taylor 2007 (2002): 53). Смысловая сложность такого типа примеров заключается в отнесенности признака к норме, которая кодируется исходной формой прилагательного (зеленый), а также в наличии в их содержании меньшего количества признака ${ }^{4}$, нежели это предполагает точка отсчета, т.е. норма признака предмета, выраженная мотивирующей основой (зелен-ыій). Учитывая сказанное, такие прилагательные можно объяснить при помощи когнитивной формулы больше формы - большая сложность содержания.

4 Эва Стрась использует термин „poziom nasycenia cechy” (дословный перевод „степень насыщенности признака”), см. Straś 2008. Об интенсивности признака см. среди других: Janus 1981, Moćko 2012. 
Значение более слабого проявления признака предмета по отношению к общепринятой норме, выраженной производящей основой, сложнее по отношению к значению наличия ничем не выделяющегося, обыкновенного качества. В „протяженной” форме зримо кодируется семантическая сложность 5 неполноты качества (красноватый < красный). Она достигается в обоих текстах за счет соответствующих друг другу суффиксальных прилагательных:

(Р) На краю неба появился зеленоватый свет - всходила луна. (с. 41)

(П) Na horyzoncie ukazało się zielonkawe światto. To wschodził księżyc. (c. 31)

Иконический принцип совпадения количества языковой формы и ее содержания реализуют еще другие аффиксальные образования, употребленные в исходном тексте, которые не всегда имеют соответствие в переводном тексте. Обращают на себя внимание следующие конструкции, подсказанные сказкой:

- префиксально-суффиксальное прилагательное подслеповатый, которое профилирует свойство плохо видящих, почти слепых глаз в выражении подслеповатые глаза:

(Р) Это была никому не страшная, пожилая черепаха Тортила с подслеповатыли глазами. (c. 63-64)

(П) Ale nie była to żmija, tylko całkiem łagodna, niemłoda już osoba, Pani Żółwiowa, trochę ślepa. (c. 47)

По отношению к полному проявлению признака глаз (и признака живых существ), лишённых зрения, способности видеть, закрепленного за непроизводным мотивирующим прилагательным слепой, атрибутивный компонент в конструкции подслеповатые глаза отражает иконический способ познания, опирающийся на принцип больше формы - большая сложность содержания.

Употребленное в переводе словосочетание trochę ślepa ('przyślepa, ślepawa') специфицирует меньшую степень проявления признака по сравнению с прилагательным исходного текста, хотя в польском языке имеется соответствие в виде сочетания prawie ślepa. Несмотря на это, категория troche ślepa реализует ту же иконическую формулу, что и подслеповатые глаза. Стоит также отметить, что в исходном тексте прилагательное подслеповаmые характеризует свойство глаз черепахи Тортилы, в то время как выражение trochę ślepa профилирует свойство черепахи Тортилы - Pani Żółwiowej, заменяя ЧАСТЬ ЦЕЛЫМ (синекдоха totum pro parte). Кроме того, в переводе не отражается метафорическая концептуализация, мотивирующая фамилию черепахи по ее форме - круглой и плоской: ЧЕРЕПАХА - ЭТО ЛЕПЕШКА.

\footnotetext{
${ }^{5}$ См. Дрожащих 2006.
} 
- суффикс превосходной степени имен прилагательных -ейщ- (-айш-), в польском языке префикс $n a j$ - в конструкции сравнительной степени прилагательного вносят значение самой высокой степени интенсивности признака по сравнению с тем же признаком у других предметов, хотя положительная форма превосходный кодирует очень хорошее, наилучшее качество, определяет предмет, превосходящий себе подобных. Иконичность прилагательных превосходнейшие - najprzedniejsze проявляется на основе формулы больше формы - больше содержания. Например:

(Р) Вот ещё! - променять превосходнейших пиявок на какой-то ключик... (с. 72)

(П) - Jeszcze czego - miałbym zamienić najprzedniejsze pijawki na jakiś tam kluczyk?... (c. 54)

- уменьшительно-ласкательные формы имен прилагательных с суффиксом -еньк- в русском языке (тоненький) $)^{6}$, с суффиксом -(i)utk-7 в польском языке (cieniutki) употреблены в значении большей степени проявления признака по отношению к норме, выраженной простой формой прилагательного, реализуют формулу больше формы - больше содержания:

(Р) Но только он начал тесать, чей-то необыкновенно тоненький голосок пропищал: (с. 7)

(П) Lecz zaledwie zaczął ciosać, czyjś niezwykle cieniutki głosik zapiszczał: (c. 7)

В обоих предложениях выступают также уменьшительно-ласкательные формы имен существительных голосок-głosik, которые выражают значение тихого, слабого голоса, и, кроме того, отражают метонимическую концептуализацию ГОЛОСОК ВМЕСТО ТОГО, КТО ГОВОРИТ ТИХИМ, СЛАБЫМ ГОЛОСОМ.

В другом фрагменте сказки

(Р) - Папа Карло, но ведь я - голенький, деревянненький, - мальчишки в школе меня засмеют. (с. 20-21)

(П) - Ależ, papo Carlo, przecież jestem goluteńki, drewniany, chłopcy w szkole będą się ze mnie śmiać. (c. 16)

уменьшительно-ласкательные формы имен прилагательных с суффиксом -еньк- голенький, деревянненький и с суффиксом -иteńk- ${ }^{8}$ goluteńki также реализуют прототипическую формулу количественной иконичности больще формы - больше содержсания. Они, однако, только усиливают значение от-

${ }^{6}$ В выражении тонкийголос прилагательное профилирует значение 'слабый, едва ощутимый', не: 'высокий’ (на основе Толкового словаря русского языка Т. Ф. Ефремовой, см. Библиография). Тоненький кодирует большую степень насыщенности признака ('очень тонкий').

7 См. Bogusławski 1991.

8 Там же. 
сутствия какой-либо одежды у персонажа сказки (голенький) и полного проявления иного признака - того, что он деревянненький. Это специфические прилагательные, ибо кодируя постоянное или временное состояние, так же как другие близкие им по значению слова типа глухой, хромой, холостой, больной, босой, лысый, отличаются тем, что признак, который они профилируют, прототипически не проявляется в большей или меньшей степени, а некоторые среди них как, например, немой, как правило, не обладают уменьшительно-ласкательной формой.

В переводе имеем дело только с частичным соответствием исходному тексту - в польском языке свободно употребляется форма качественного прилагательного goluteńki (значительно чаще - golusieńki), в свою очередь, уменьшительно-ласкательные формы от относительного прилагательного drewniany не образуются.

- уменьшительно-ласкательные формы наречий:

(Р) - Вали, вали хорошенько! (с. 11)

(П) - Wal, wal, a mocno! (c. 9)

В переводе выделенная конструкция исходного текста хорошенько в функции способа действия заменяется неуменьшительной формой наречия тоспо. Оно отражает большую интенсивность процесса, выполненного с большой силой, которая подчеркивается союзом а ( бленным для усиления эмоционального отношения к тому, что происходит. В этом случае иконическая формула больше формь - больше содержания реализуется в переводе за счет данного выражения.

\section{ЗАКЛЮЧЕНИЕ}

На основе сказки Алексея Н. Толстого, текст которой является богатым источником примеров проявления иконичности вообще, количественной в частности, можно отметить следующее. Количественная иконичность проявляется на всех уровнях языка. В сказке, с одной стороны, выделяются такие разновидности количественной иконичности, которые часто встречаются в до сих пор появившейся научной литературе и получили достаточно полную характеристику на примере разных языков. Имеется в виду прежде всего фонетическая редупликация, которая может пониматься как общепринятая языковая способность конструировать событие. Она опирается на формулу больше формы - больше содержания, конкретизируемую понятием большой степени интенсивности явления, о котором говорится в высказывании. 
С другой стороны, имеются в виду грамматические средства языка, среди которых обращает на себя внимание словесная редупликация как иная возможность реализации в общении такого способа познания действительности, каким является количественная иконичность. Анализ как текста сказки, так и ее перевода, позволяет заметить, что лексическая редупликация представляет собой непростое языковое явление. Его сложность заключается в наличии ранообразных выражений, которые кодируют данную иконичность, в связанных с ними значениях, которые проявляются в определенных контекстах, и отражают или конкретизируют прототипическую формулу количественной иконичности больше формы - больше содержания.

Приведенные характеристики позволяют также сформулировать более общий вывод о том, что количественная иконичность как способ познания действительности, отраженный в языковой единице, представляет собой случай категории, образованной многими значениями. Одно из них считается прототипическим (больше формы - больше содержания), остальные - это периферийные понятия. Как одни, так и другие объединяются схематическим понятием категории квантитативной иконичности, которое можно определить как подобие количества формы и содержания. Его выделение позволяет понимать данную разновидность иконичности как когерентную категорию, гештальт. Она является результатом познавательных процессов, в основе которых лежат способности носителей языка наблюдать, сравнивать и находить или устанавливать сходства между предметами. Это замечание подтверждает одно из основных положений когнитивной грамматики о радиальном характере языковых категорий, составленных прототипическим и периферийными понятиями, объединенных абстрактным значением, отражающих способности познания действительности говорящими.

В контексте количественной иконичности то новое, подмеченное на примере обоих синтетических языков как их особенное свойство, - это символические единицы, образованные морфологическими способами, такие, например, как уменьшительно-ласкательные формы имен прилагательных, существительных, наречий, префиксально-суффиксальные прилагательные и другие. На их семантику оказывают влияние компоненты, которые создают конструкцию: в составе производного слова это мотивирующая основа вместе с аффиксальными морфемами, а также присоединяемое им слово. Они сложным образом реализуют формулу больше формы - больше содержания. На этой основе можно говорить о пополнении уже представленных результатов исследований иконичности за счет приведенных на основе сказки и ее перевода типов конструкций, свойственных русскому и польскому языкам.

С точки зрения сравнения исходного и переводного текстов в случае, когда tertium comparationis составляет количественная иконичность, в переводе на уровне фонетической иконичности заметны некоторые раз- 
личия, которые являются эффектом авторской интерпретации подлинного текста. Есть также различия, вызванные несоответствием языковых систем. Наконец наблюдаются такие переводческие решения, в результате которых сохраняется эквивалентность подлинному тексту. В таком случае имеем дело с отраженными в речи общими способами познания действительности.

\section{Библиография}

Википедия - свободная энциклопедия, https://ru.wikipedia.org/wiki/\%D0\%A1\%D0\%BF\%$\mathrm{D} 0 \% \mathrm{BB} \% \mathrm{D} 1 \% 8 \mathrm{E} \% \mathrm{D} 1 \% 88 \% \mathrm{D} 0 \% \mathrm{BA} \% \mathrm{D} 0 \% \mathrm{~B} 0$.

Дрожащих Н. В. (2006), Синергетическая модель иконического пространства языка, Автореферат диссертации на соискание ученой степени доктора филологических наук, Барнаул, http://liconism.ru/images/documents/288/\%D0\%94\%D1\%80\%D0\%BE\%D0\%B6\%D0\%B0\%D1\%89\%D0\%B8\%D1\%85\%20\%D0\%90\%D0\%94\%D0\%94\%20 $\% \mathrm{D} 0 \% \mathrm{~A} 1 \% \mathrm{D} 0 \% \mathrm{~B} 8 \% \mathrm{D} 0 \% \mathrm{BD} \% \mathrm{D} 0 \% \mathrm{~B} 5 \% \mathrm{D} 1 \% 80 \% \mathrm{D} 0 \% \mathrm{~B} 3 \% \mathrm{D} 0 \% \mathrm{~B} 5 \% \mathrm{D} 1 \% 82 \% \mathrm{D} 0 \% \mathrm{~B} 8 \%-$ D $1 \% 87 \%$ D $0 \%$ B $5 \%$ D $1 \% 81 \%$ D $0 \%$ B A $\%$ D $0 \%$ B $0 \%$ D $1 \% 8$ F $\% 20 \%$ D $0 \%$ BC $\%$ D $0-$ $\%$ B E \% D 0 \% B 4 D 0 \% B $5 \%$ D $0 \%$ B B \% D $1 \% 8$ C \% $20 \%$ D $0 \%$ B $8 \%$ D $0 \%$ B A \% D $0 \%$ BE $\%$ D $0 \%$ B D \% D $0 \%$ B $8 \%$ D $1 \% 87 \%$ D $0 \%$ B $5 \%$ D $1 \% 81 \%$ D $0 \%$ B A $\%$ D $0 \%-$ B E \% D $0 \%$ B $3 \%$ D $0 \%$ B E \% $20 \%$ D $0 \%$ B F \% D $1 \% 80 \%$ D $0 \%$ B E \% D $1 \% 81$ $\%$ D $1 \% 82 \%$ D $1 \% 80 \%$ D0 $\%$ B $0 \%$ D0 $\%$ BD $\%$ D $1 \% 81 \%$ D $1 \% 82 \%$ D0 $\%$ B2\%D0\%B0\%20 $\% \mathrm{D} 1 \% 8 \mathrm{~F} \% \mathrm{D} 0 \% \mathrm{~B} 7 \% \mathrm{D} 1 \% 8 \mathrm{~B} \% \mathrm{D} 0 \% \mathrm{BA} \% \mathrm{D} 0 \% \mathrm{~B} 0 . \mathrm{pdf}$.

Елина Е. Н. (2010), Когнитивные теории значения: Когнитивная грамматика Р. Лангакера, Вестник Красноярского государственного педагогического университета им. В. П. Астафьева, № 2, http://cyberleninka.ru/article/n/kognitivnye-teorii-znacheniya-kognitivnayagrammatika-r-langakera.

Ефремова Т. Ф., Толковый словарь русского языка, http:/что-означает.рф, Сборник словарей; Ефремовой, Ожегова, Шведовой.

Кибрик А., Иконичность, http://www.krugosvet.ru/enc/gumanitarnye_nauki/lingvistika/IKONICHNOST.html?page=0,0, Энииклопедия Кругосвет.

Лангакер Р. В. (1998), Природа грамматической валентности, «Вестник Московского университета. Серия 9: филология», № 5, с. 73-111.

Лангаккер Р. В. (1997), Модель, основанная на языковом употреблении, «Вестник Московского университета», Серия 9: филология, № 4, с. 159-174, № 6, с. 101-123.

Мельник Я. (ред.) (2004), Словарь криминального и полукриминального мира: мат, сленг, жаргон, http://fenya.academic.ru/8410/\%D0\%A8\%D1\%83\%D1\%88\%D0\%B0\%D1\%80\%D $0 \% \mathrm{~B} 0$.

Мильдзихова А. К. Иконичность современного стихотворного текста как лингвосемиотический феномен (на материале немецких свободных ритмов), http://www.dslib. net/jazyko-znanie/ikonichnost-sovremennogo-stihotvornogo-teksta-kak-lingvosemioticheskij-fenomen.html.

Род Совки - Otus, http://www.apus.ru/site.xp/052052057.html.

Рыжих М. В. (2011), Роль иконичности в авторской англоязычной сказке, «Вестник Московского государственного лингвистического университета», № 623, Научная библиотека КиберЛенинка: http://cyberleninka.ru/article/n/rol-ikonichnosti-v-avtorskoy-angloyazychnoy-skazke\#ixzz4cQmmKCbb. 
Толстой А. (1988), Золотой ключик или приключения Буратино, Вильнюс.

Флаксман М. А. (2015), Диахроническое развитие звукоизобразительной лексики английского языка, т. I: дис. кандидата филол. наук: 10.02.2004, Санкт-Петербург, https://disser.spbu. ru/files/disser2/disser/Flaksman_dissertazia.pdf.

Atlas rozpoznawania sów. Syczek (Otus scops), http://sowy.sos.pl/atlas-rozpoznawania-sow/syczek-otus-scops/.

Bańko M. (2008), Wspótczesny polski onomatopeikon. Ikoniczność w języku, Warszawa.

Bańko M. (2009), Słownik onomatopei, czyli wyrazów dźwięko- i rucho-naśladowczych, Warszawa.

Bogusławski A. (1991), Polski sufiks -utki-, „Poradnik Językowy” 5, c. 174-179, https://poradnik-jezykowy.uw.edu.pl/actions/download_document/1035?type=text.

Chłopek-Labo M. (2013), Ikoniczność a interpretacja. Na przykładzie opowiadania Borisa Akunina „Byt i się zmyt, czyli śmierć zapomniana z tomu Historie cmentarne”, [в:] ред. E. Tabakowska, N. Palich, A. Nowakowski, Ikoniczność w języku, literaturze i przekładzie, Kraków, c. 47-52. Janus E. (1981), Wykładniki intensywności cechy (na materiale polskim i rosyjskim), Wrocław.

Langacker R. W. (2009), Gramatyka kognitywna. Wprowadzenie, tł. E. Tabakowska [i in..], Kraków. Moćko N. (2012), Anielsko cierpliwy i piekielnie inteligentny - o intensyfikacji w profanum za pomoca sacrum, "Linguarum Silva" 1, c. 37-54. http://bazhum.muzhp.pl/media//files/Linguarum_Silva/Linguarum_Silva-r2012-t1/Linguarum_Silva-r2012-t1-s37-54/Linguarum_Silvar2012-t1-s37-54.pdf

Straś E. (2008), Kategoria intensywności we frazeologii języka polskiego i rosyjskiego, Katowice.

Tabakowska E. (1995), Gramatyka i obrazowanie. Wprowadzenie do językoznawstwa kognitywnego, Kraków.

Tabakowska E. (2001), Językoznawstwo kognitywne a poetyka przekładu, Kraków.

Tabakowska E. (2006), Ikoniczność znaków i struktur językowych jako typ podobieństwa, [w:] ред. H. Kardela, Z. Muszyński, M. Rajewski, Kognitywistyka. Podobieństwo, Lublin.

Tabakowska Е. (ред.). (2006), Ikoniczność znaku: słowo-przedmiot-obraz-gest, Kraków. E. Tabakowska, N. Palich, A. Nowakowski (ред.) (2013), Ikoniczność w języku, literaturze i przekładzie, Kraków.

Taylor J. R. (2007), Gramatyka kognitywna, tł. M. Buchta, Ł. Wiraszka, Kraków.

Tołstoj A. (2014), Złoty kluczyk, czyli niezwykłe przygody pajacyka Buratino, tł. J. Tuwim, Poznań.

\title{
ON QUANTITATIVE ICONICITY IN A FAIRY TALE BY ALEKSEY TOLSTOY THE GOLDEN KEY, OR THE ADVENTURES OF BURATINO AND ITS TRANSLATION INTO POLISH
}

\author{
(Summary)
}

The paper discusses a diagrammatic type defined as a quantitative iconicity principle and one of the aspects of imaging within the theory of cognitive grammar developed by Ronald W. Langacker. On the example of a fairy tale by A. N. Tolstoy, it distinguishes manners of categorization of the world, which follow a specific semiotic principle in Russian. The findings of the analysis enable treating the principle as an example of a radial category. Further, the article includes the results of comparison between Russian structures and their translation into Polish, with the quantitative iconicity applied as tertium comparationis.

Keywords: diagrammatic iconicity, semiotic principle of quantitative iconicity, categorization, conceptualization, radial category. 


\section{О КОЛИЧЕСТВЕННОЙ ИКОНИЧНОСТИ В СКАЗКЕ АЛЕКСЕЯ ТОЛСТОГО ЗОЛОТОЙ КЛЮЧИК ИЛИ ПРИКЛЮЧЕНИЯ БУРАТИНО И ЕЕ ПОЛЬСКОМ ПЕРЕВОДЕ}

(Резюме)

В настоящей статье рассматривается тип диаграмматичности, определяемый как принцип количественной иконичности и один из аспектов образности в теории Рональда В. Лангакера. На примере сказки А. Н. Толстого выделяются способы категоризации мира, которые в русском языке реализуют данный семиотический принцип. Результаты анализа позволяют воспринимать количественную иконичность как пример радиальной категории. В статье проводится также сравнение конструкций русского языка с их польским переводом, tertium comparationis составляет количественная иконичность.

Ключевые слова: диаграмматическая иконичность, семиотический принцип количественной иконичности, категоризация, концептуализация, радиальная категория. 